\title{
Uma análise fenomenológica existencial do adolescente em conflito com a lei
}

\section{An existential phenomenological analysis of adolescents in conflict with the law}

\section{Gabriela Laureano Guedes ${ }^{\dagger *}$, Thaís Leite Reis *}

Como citar esse artigo. GUEDES, G.L.; REIS, T.L. Uma análise fenomenológica existencial do adolescente em conflito com a lei. Revista Mosaico, v.12, n.1, p. 105-112, 2021.

Nota da Editora. Os artigos publicados na Revista Mosaico são de responsabilidade de seus autores. As informações neles contidas, bem como as opiniões emitidas, não representam pontos de vista da Universidade de Vassouras ou de suas Revistas.

\author{
Resumo
}

Os conflitos com a lei ocorridos na fase da adolescência e seus desdobramentos na sociedade suscitam uma reflexão acerca da atuação dos operadores das políticas públicas e da garantia da proteção da infầncia e da juventude através da sensibilização e da responsabilidade, fomentando a liberdade e a dignidade e não contribuindo para práticas punitivas. Este trabalho tem como objetivo apresentar a construção social da adolescência de modo individualizado e excludente, sendo o ato infracional visto como uma realidade condicionada e determinante na existência do adolescente pobre, podendo repercutir no surgimento de estereótipos e discriminação. Para isso, o fundamento do pensamento fenomenológico-existencial de Jean Paul Sartre traz à luz a existência como uma indeterminação e a constituição do sujeito a partir da sua experimentação do mundo nas relações vivenciadas em liberdade.

Palavras-chave: Adolescência; Medida socioeducativa; Liberdade; Existencialismo.

\begin{abstract}
The conflicts with the law that occurred in the adolescence phase and its consequences in society raise a reflection about the performance of public policy operators, in order to guarantee the protection of childhood and youth, through sensitization and responsibility, promoting freedom and dignity and not contributing for punitive practices. This work has the objective of presenting the social construction of adolescence in an individualized and exclusive way, being the infraction act seen as a conditioned reality and determinant in the existence of the poor teenager, which can have repercussions in the emergence of stereotypes and discrimination. For this, the foundation of Jean-Paul Sartre's phenomenological-existential thought in light of existence as an indeterminacy and the constitution of the subject, from his experimentation of the world in relationships experienced in freedom.

Keywords: Adolescence; Socio-educational measure; Freedom; Existentialism.
\end{abstract}

\section{Introdução}

A adolescência tem se tornado uma fase da vida constantemente associada aos conflitos intersubjetivos (COUTINHO, 2009) e intensamente atravessada por questões socioculturais, como classe econômica e raça. Partindo desse pressuposto e baseando-nos em Coimbra e Nascimento (2005), que fazem um questionamento acerca da pobreza e da criminalidade, o presente trabalho propõe uma reflexão fenomenológico-existencial do adolescente em conflito com a lei-mais especificamente no âmbito da adolescência pobre e preta -, questionando se a experiência social pode ser determinante na prática do ato infracional e consequentemente na privação de liberdade ${ }^{1}$. Busca-se também expor as possibilidades de ser e a forma como o indivíduo se relaciona com o mundo a partir do que lhe foi dado (AGUIAR, 2008).

A relevância do tema justifica-se pela superlotação das unidades de medidas socioeducativas (MSE) e por conta da política de encarceramento dos adolescentes em conflito com a lei, tendo em vista a possibilidade iminente de uma redução da maioridade penal alavancar ainda mais esse quantitativo. Além disso, os estereótipos socialmente construídos acerca da adolescência - como, por exemplo, a ideia de que se trata de uma fase da vida rebelde e inconsequente, com condutas que apontam para um potencial risco - encapsulam o sujeito e determinam a sua existência (COUTINHO, 2009).

A justificativa do tema aponta ainda para um olhar de estranhamento desses estereótipos, principalmente em relação ao adolescente em cumprimento de MSE e para além do ato infracional cometido, ou seja, enquanto sujeito determinado socialmente, mas em relação com

Afiliação dos autores

† Graduanda em Psicologia, Universidade de Vassouras, Vassouras, Rio de Janeiro, Brasil

* Mestranda em Psicologia Social, Universidade de Vassouras, Vassouras, Rio de Janeiro, Brasil

* Email de correspondência:gabrielalguedes.psico@gmail.com 
o mundo, sendo livre e responsável por suas ações. Aponta-se ainda a necessidade de análise das condições de cumprimento da medida socioeducativa e da possível violação de direitos por meio de práticas punitivas, que podem prolongar o tempo de internação, afetando a reinserção social e o desenvolvimento psíquico, bem como a criação do projeto existencial desses sujeitos.

A metodologia utilizada neste trabalho será uma revisão de literatura com base no pensamento existencialista, que trará uma reflexão acerca do adolescente em conflito com a lei, tendo como referência a filosofia de Jean-Paul Sartre e outros autores desta base filosófica.

\section{Adolescência e suas facetas na contemporaneidade}

A adolescência é uma fase caracterizada pela transição entre a infância e a vida adulta. Este período de formação do sujeito é atravessado por aspectos biopsicossociais em interação, tais como fatores biológicos, culturais e psicológicos (personalidade, comportamento, humor etc.), que podem influenciar o desenvolvimento (COUTINHO, 2009). Segundo o autor supracitado, durante os séculos XVIII e XIX, a adolescência era vista como uma fase de indeterminações e dependência, na qual a família e a sociedade aproveitavam a vulnerabilidade dos indivíduos para moldá-los para a vida adulta, acrescentando-lhe valores éticos, morais e sociais. No entanto, essa concepção sofreu uma transformação ao longo do tempo.

A construção social da adolescência parte de fatores socioculturais, como cor, classe econômica, orientação sexual, religião etc., o que torna as questões relacionadas a esta fase da vida ainda mais indeterminadas e complexas. Este campo - antes vazio, mas também fértil - abre espaço para um ideal de adolescência, momento da vida marcado pela busca da liberdade e do prazer (COUTINHO, 2009).

O mundo moderno traz o homem como indivíduo detentor de si, com autonomia e possibilidade de escolha, tendo como base de suas ações a razão - diferenciandose, portanto, da estrutura que busca fundamentalmente atender às ordens religiosas e cujo objetivo é estar cada vez mais próximo do divino. A Revolução Francesa, que teve início no ano de 1789, é um dos pilares para esta mudança de paradigma. Seu principal objetivo era a reivindicação da queda do regime absolutista monárquico, derrubando privilégios feudais, religiosos e aristocratas e buscando por liberdade, igualdade e fraternidade. Nesse sentido, os indivíduos procuraram afastar as determinações políticas e sociais e as legitimações de ordem divina (COUTINHO 2009).

Ao se pensar a adolescência, é preciso destacar o cenário social no qual esta está inserida para que se entenda qual a premissa das escolhas e como os modos de ser se dão. Em outras palavras, faz-se necessário considerar o que Schneider (2011) denomina placenta social: a matriz identitária que versa sobre o lugar social, como a família na qual a criança está inserida ao nascer e onde desenvolve suas potencialidades psicológicas, sociais e relacionais, por meio de segurança e orientação e através da visão do outro. Tal conceito compreende todo o desenvolvimento infantil e constitui o sujeito até o seu nascimento existencialmente, ou seja, até a sua inserção em outros grupos, como escola, igreja, vizinhança etc.

Atualmente, é possível perceber como as estruturas sociais e econômicas influenciam e criam padrões de subjetivação. $\mathrm{O}$ industrialismo e seus reflexos na sociedade tendem a estigmatizar aqueles que economicamente não se encaixam no padrão visto como ideal, no qual o capitalismo rege as formas do indivíduo se comportar e os bens são responsáveis por determinar quem é bom ou mal (COIMBRA; NASCIMENTO, 2005). Com base nesse cenário político-econômico e na herança escravocrata do país, pode-se identificar um comportamento excludente dos desviantes. Como explica César (1999, p. 1) "a implantação das reformas higienistas nos centros urbanos foi responsável pelo aparecimento de personagens que se encontravam à margem da ordem burguesa".

Forjam-se papéis sociais dados como virtuosos e posições que se inclinam a um potencial perigo. As famílias de classes sociais mais baixas ocupam os centros urbanos de forma intensa a fim de buscar sustento para a casa e acabam terceirizando a criação dos filhos ao ambiente das ruas. Com isso, os adolescentes pobres se encontrariam numa posição de vulnerabilidade para o perigo. As questões éticas e morais estão diretamente ligadas ao padrão eurocêntrico de cor e às estruturas econômica e familiar. Logo, as famílias "disfuncionais", que, de acordo com a definição de César(1999), correspondem àquelas que não conseguem oferecer a sua prole os subsídios afetivos e materiais, seriam consideradas responsáveis pelos problemas comportamentais relacionados à adolescência.

Cabe ressaltar que a adolescência destacada neste trabalho se refere aos indivíduos pobres, que são colocados à margem da sociedade. Com base em Cadoret (apud COUTINHO, 2009), as questões relacionadas à adolescência se mostram como um fator de mal-estar cultural e estão diretamente relacionadas a fatores socioeconômicos. De acordo com o IBGE (VIEIRA, 2016), duas a cada três pessoas pobres são também negras. Soma-se a isso o fato de que mais de $54 \%$ da população brasileira é composta por pretos e pardos. Estes dados apontam a necessidade de pensar a realidade da população, especialmente os adolescentes, para além da homogeneidade de padrões ideais de 
comportamento (COIMBRA; NASCIMENTO, 2005).

No que diz respeito à relação do adolescente com o mundo, Heller (apud COUTINHO, 2009, p.197) aponta que "a adolescência nos anos 60 e 70 é frequentemente associada aos movimentos de crítica política e cultural [e] a dos anos 80 , às galeras ou às gangues". Cabe ressaltar que esses movimentos estão diretamente atrelados ao espaço geográfico, à situação econômica e aos interesses em comum, podendo, portanto, constituir sua identidade (COUTINHO, 2009). Nessas aproximações surgem as tribos, segmentação do tecido social que representa "um novo modo de movimentação social no espaço urbano, bem como de apropriação dos diversos códigos sociais que nele convivem" (SPOSITO apud COUTINHO, 2009, p.198).

A respeito da construção de identidades, Vitelli (2009, p. 54) afirma que

há sempre algo novo que nos motiva a buscar não só respostas, mas questionamentos sobre o tempo presente. Qualquer fase da vida, faixa etária, grupo social, traz consigo um conceito relacional, que estará ligado a símbolos e valores pertinentes de cada época.

Os espaços urbanos são esquematizados por uma evidente demarcação social de território que separa o seguro do perigoso e o pobre do rico. A criminalização da pobreza é marcada pela restrição do jovem pobre e preto aos guetos, entregue a determinações sociais que tornam suas possibilidades de ser definidas e inquestionáveis. No presente trabalho, a inquietude da investigação acerca da adolescência está além de questões estéticas, atentando-se principalmente aos efeitos que a sociedade contemporânea exerce sobre a constituição dessa fase (VITELLI, 2009).

A pobreza e a produção de subjetividades estão relacionadas à historicidade do país no âmbito da escravidão e do sistema econômico: o capitalismo (COIMBRA; NASCIMENTO, 2005). Logo, o pobre e o preto estariam fadados ao que há de pior na nossa sociedade. Suas escolhas seriam perpassadas pela realidade que ocupam, ou seja, haveria um lugar específico de ocupação e apropriação, associando pobreza e degradação moral.

Todavia, segundo Sartre (apud CORBIANO; BERGAMO, 2016, p. 266), "o objeto é transcendente às consciências que o apreendem e é nele que se encontra a sua unidade". Apesar das determinações sociais, o indivíduo é livre para escolher dentre as facticidades. Não há essência previamente dada, portanto, é no movimento dialético entre interior e exterior, dentro e fora, de ser no mundo e com o mundo que a existência de dará de modo imprevisível, constituindo o sujeito por meio dessa relação intersubjetiva (CORBIANO; BERGAMO, 2016). O existencialismo de Sartre (1997) parte do pressuposto de que a existência, desde o início, surge da indeterminação. Primeiramente é preciso distanciar-se de teorias da personalidade e da aprendizagem na hora de pensar a criança e, por conseguinte, o adolescente. Só a partir de então, deve-se pensar o fenômeno da experiência como ela se mostra (FEIJOO, 2011).

A filosofia existencialista tem como fundamento a construção do sujeito para além de cristalizações e entificações. "É no decorrer de sua vida que a criança tomará para si o seu modo de ser em sua incompletude e sempre em jogo com as determinações do mundo" (FEIJOO, 2011, p. 186). O desenvolvimento humano precisa ser visto em abertura, para que se dê a partir das vivências do adolescente, visando a possibilidade da construção de um modo de ser autêntico. O Homem, em síntese, é a possibilidade de vir a ser (FEIJOO, 2011).

\section{$O$ ato infracional, a adolescência e as medidas socioeducativas}

A discussão do ato infracional (caracterizado como crime ou contravenção penal) na adolescência surge concomitantemente à necessidade de pensarmos a ação do delito, relacionando-o a um histórico de violência estrutural que atravessa o contexto social do adolescente. Segundo Minayo (2001), percebe-se que a violência contra crianças e adolescentes se faz presente como um fato social. Sendo assim, os fatores culturais perpassam significativamente o contexto infanto-juvenil. A realidade do país indica a violência de diversas formas: estrutural, doméstica e delinquencial (MINAYO, 2001). Cabe aqui a vinculação entre as violências estruturais, praticadas pelos agentes do Estado e pela sociedade, e as delinquenciais, que apontam para a prática de crimes. Portanto, os cenários sociais que sustentam práticas de desigualdade e sutilmente causam sofrimento às classes econômicas mais baixas - negando oportunidades iguais de acesso à educação, lazer, saúde e principalmente a dignidade humana - são consideradas violências estruturais (MINAYO, 2001).

No Brasil, uma manifestação de violência estrutural na infância e na juventude ocorre no trabalho infantil e na vivência em situação de rua. Essa parcela da população é colocada à margem pela sociedade, tendo seus direitos negados. Aponta-se aqui a necessidade de nos destinarmos à compreensão da violência na adolescência de um modo singular, que varia em suas manifestações e argumentações (MINAYO, 2001). Além da desigualdade social, o país é marcado pela concentração de renda nas mãos de uma pequena parte da população. Dados do IBGE (2019) apontam que "em 2018, o rendimento médio mensal real do $1 \%$ da população com maiores rendimentos era de $\mathrm{R} \$ 27.744$, o que corresponde a 33,8 vezes o rendimento dos $50 \%$ da população com os menores rendimentos ( $\mathrm{R} \$ 820)$ ".

Com isso, evidenciam-se os efeitos da 
desigualdade social sobre a juventude brasileira, como as restrições de acesso à educação, cultura e saúde. A naturalização dos padrões sociais excludentes está presente também nas mídias, que justificam situações de violência, associando-as à pobreza e à criminalidade. Desse modo, a população pobre e preta é constantemente marginalizada pela sociedade e pelo Estado (MINAYO, 2001).

O Estatuto da Criança e Adolescente (ECA) faz parte do ordenamento jurídico que visa proteger aquele que ainda não atingiu a maior idade e que está em situação de vulnerabilidade social e de risco. Neste sentido, engloba crianças e adolescentes que vivenciam violência, como, por exemplo, aqueles que cometem um ato infracional. Em casos de conflito com a lei, é dever do Estado garantir condições para o cumprimento das medidas e para o integral desenvolvimento físico, psíquico e social desses indivíduos. Isto se dá através do acesso à educação, cursos profissionalizantes, saúde e convivência comunitária e familiar, a fim de que haja uma reinserção na sociedade com dignidade e responsabilidade, ressignificando $\mathrm{o}$ ato cometido (SPOSATO, 2004). Com isso, tendo como princípio os direitos e a proteção integral garantidos pelo ECA, corrobora-se que, num contexto de prática de ato infracional, é direito do adolescente receber o amparo necessário do Estado para desenvolver-se de forma plena. Nesse sentido, é necessário criar estratégias articuladas entre políticas públicas, que possibilitem ao adolescente atendido pelo sistema socioeducativo o redirecionamento social e a sensibilização pelo ato cometido (BRASIL, 2019).

Direcionado por essa premissa, o ECA(BRASIL, 1990), em seu artigo 121, prevê medidas de caráter mais rigoroso em certos casos de atos infracionais, como, por exemplo, a de restrição total de liberdade. No entanto, estas alternativas não podem ser vistas em um caráter punitivo, mas sim como parte do Plano Individual de Atendimento (PIA) e da orientação de seus direitos e deveres, capaz de ressignificar o projeto existencial do sujeito. Regina Novaes (apud VITELI, 2009) sinaliza o valor da participação social do adolescente e o engajamento no seu plano a fim de fazer valer seus direitos, colocando em questão preconceitos intrínsecos à sociedade.

Todavia, a realidade das condições de cumprimento das MSE no Brasil está em desacordo com o previsto no Sistema Nacional de Medida Sócio Educativa(SINASE), que-apesarde estabelecermedidas pedagógicas de internações permanentes, internações provisórias, medidas de semiliberdade, liberdade assistida (LA) e prestação de serviços comunitários (PSC) - é permeado por violência institucional. Em consonância com BARBOSA (2013 apud AZEVEDO, AMORIM e ALBERTO, 2017) e Moreira (2011), a violência institucional em casos de MSE se caracteriza pelas práticas do Estado, de instituições ou agentes, sob a justificativa de disciplinar e controlar os corpos.

Segundo Sposato (2004), a internação permanente é prevista em casos nos quais o adolescente já tenha praticado fatos análogos aos crimes. Tratase da medida mais gravosa dentre as socioeducativas e deve ser aplicada em último caso. Sendo assim, seu objetivo não restringe-se ao isolamento social, mas sim, como visto anteriormente, contempla a orientação e a responsabilização do adolescente em conflito com a lei.

$\mathrm{Na}$ internação provisória, diferentemente do que ocorre na internação permanente, ainda não se tem o devido processo que reconhece o adolescente como autor do fato análogo ao crime. O objetivo é assegurar o cumprimento de medidas futuras no caso de eventual apreensão do adolescente infrator. Assim, deve ser adotada de forma excepcional e para um fim específico, qual seja a futura adoção da internação permanente. A restrição de liberdade não é o fim que se deseja com a lei, mas sim uma reinclusão social plena do adolescente infrator, levando-o a elaborar uma perspectiva de mundo e de si mesmo como sujeito de direitos, favorecendo a habilidade de descobrir, produzir, criar e refletir sobre sua conduta (BRASIL, 2019).

Já as medidas de semiliberdade representam uma forma mais branda de restrição do direito de ir e vir e possuem caráter menos gravoso pelo fato de possibilitarem ao adolescente o convívio com a família nos finais de semana e a execução de atividades externas que forneçam novas possibilidades de ser (SPOSATO, 2004). O Sinase (2019) também traz o cumprimento das medidas em meio aberto (liberdade assistida e prestação de serviços comunitários), cuja responsabilidade é delegada aos municípios e o objetivo é promover ações pedagógicas que proporcionem ao adolescente novas possibilidades. Essas medidas são preconizadas em detrimento da restrição de liberdade, pois possibilitam ao adolescente a convivência com a família e a sociedade, fazendo disso um instrumento de fortalecimento dos vínculos sociais.

Os adolescentes em cumprimento de ambas as medidas em meio aberto são direcionados ao Centro de Referência Especializado de Assistência Social (CREAS), equipamento de proteção especial às violações de direitos da assistência social. A liberdade assistida se dá através de um acompanhamento direcionado, com orientação de uma equipe multidisciplinar, para que se trace um plano de atendimento individual que culmine em um projeto de inclusão social e de acesso aos direitos e deveres do adolescente. Já o cumprimento de prestação de serviços comunitários possui o intuito de execução gratuita de tarefas de interesse comum.

De acordo com os dados do levantamento anual do SINASE (BRASIL, 2019), em 2017 havia 143.316 adolescentes em atendimento socioeducativo em todo 
o país, sendo esse número dividido entre todas as modalidades de atendimentos existentes no sistema. Cabe ressaltar as características étnico-raciais dos adolescentes em cumprimento de MSE para entender de que forma ocorrem os processos de subjetivação em privação ou restrição de liberdade.

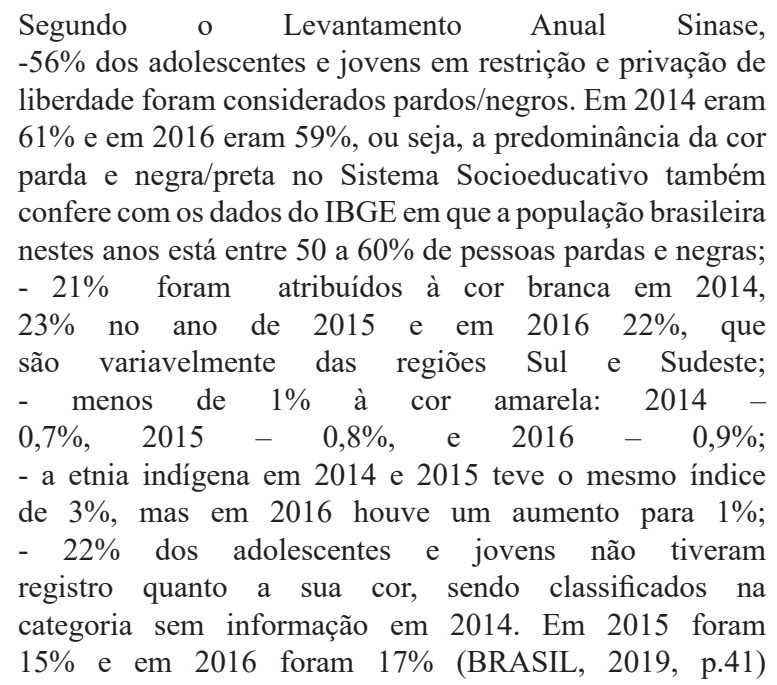

O documento do Sinase (BRASIL, 2019) restabelece o princípio ratificado pelo ECA (artigos 94 e 124), que dispõe sobre o espaço físico das unidades de internação e internação provisória e sobre a obrigação do Estado de oferecer os subsídios necessários. No ano da formulação do Sinase, Rocha (apud BRASIL, 2006) constatou que os ambientes físicos das unidades de internação não atendiam aos requisitos da proposta pedagógica, uma vez que faltavam espaços para prática de atividades físicas e de lazer e que as condições de manutenção e limpeza eram precárias. Já o levantamento mais recente mostra um panorama mais específico das unidades federativas, evidenciando que, apesar de todo o avanço, algumas unidades ainda não cumprem em totalidade o que está estabelecido por lei (BRASIL, 2019).

É de suma importância atentar para as formas e ambientes de operacionalização dessas medidas, que devem possuir caráter educativo e não somente disciplinador, para que assim os direitos do adolescente não sejam violados. É necessário articular redes que possibilitem uma análise ampla do contexto de cada indivíduo, determinando de que maneira as medidas irão se tornar ou não instrumento de transcendência ao ato infracional (BRASIL, 2019).

Isto posto, a ineficácia da internação dos adolescentes em um sistema com elementos de violência institucional, semelhante ao ambiente de prisões, torna ainda mais hostil a convivência entre eles, uma vez que estão sendo punidos perversamente. No entanto, as MSE possuem o objetivo pedagógico de prevenir a reincidência dos atos infracionais e promover a ressocialização com base na proteção integral, que, em sua premissa, visa garantir as necessidades básicas da criança e do adolescente (CUSTÓDIO, 2008). Analisase, então, se o sistema pode levar o adolescente em conflito com a lei à transcendência do determinismo social ou fomentar práticas excludentes e punitivas, sendo dever do Estado a efetivação de políticas públicas de proteção para combater situações de vulnerabilidade (BRASIL, 1990).

Salientam-se as políticas públicas voltadas para a juventude, como o Código de Menores (BRASIL, 1979), que preservava a ordem e direcionava o Estado à responsabilidade de reeducar e recuperar o "menor". Este termo, a princípio, tinha como significado a menoridade, porém o sentido dado na própria política caracteriza-o como um estereótipo de exclusão dos que cometiam os atos infracionais ou estavam em situação irregular. Este último contexto sugere uma patologia social e uma "incompetência" das famílias em conceder conhecimento, necessidades básicas e afeto aos seus filhos, que acabam destinados às vias públicas, aos vícios e à "escola do crime" (CUSTODIO, 2008). O ECA vem para romper com esse pensamento punitivo e excludente, afirmando o valor da criança e do adolescente enquanto sujeitos de direitos e garantindo condições físicas e emocionais de desenvolvimento (BRASIL, 1990).

Por isso, é importante reconhecer a autonomia do adolescente como parte integrante desse processo, vislumbrando a liberdade para além da representação de um potencial perigo, ou seja, enquanto responsabilidade pelas ações praticadas e participação ativa na construção de novas respostas sociais (CFP, 2011). Além disso, é importante fazer com que a execução de medidas socioeducativas se torne uma ferramenta de inclusão social, o que requer também fortalecer as redes sociais das quais o adolescente faz parte, propiciando encontros que posicionem sua relação no mundo e oferecendo educação e práticas profissionalizantes (BRASIL, 2019).

O espaço de execução das medidas socioeducativas
como ambiente socializador e educativo deve favorecer
a esse adolescente construir uma visão de mundo e
de si mesmo como sujeito de direitos, estimulando a
capacidade de descobrir, produzir, criar e refletir sobre
sua conduta, atendendo aos objetivos das medidas
socioeducativas previstos no SINASE (BRASIL, 2019).

Até então, expusemos como os contextos históricos, sociais e econômicos estão relacionados à constituição da adolescência. As condições para o cumprimento das MSE devem ser garantidas, bem como os direitos dos indivíduos, a fim de que se transcenda a relação punitiva e seja possível uma reflexão consciente acerca da Liberdade e da responsabilidade. A atuação profissional dos operadores das medidas socioeducativas deve suscitar práticas que tenham 
como objetivo romper com os entraves e determinações do sistema, reposicionando o adolescente dentro do seu projeto existencial e de suas vivências sociais (BRASIL, 2019).

\section{Privação de liberdade e encapsulamento do sujeito}

Seria possível o adolescente pobre romper com as determinações do contexto social e transcender as facticidades? Com base em Schneider (2011), o indivíduo é um ser histórico, ou seja, um sujeito que baseia suas escolhas primeiramente nas experiências de situações vivenciadas em seu horizonte social. Sendo assim, sua constituição ocorre de modo espontâneo, a partir de uma consciência irrefletida do fenômeno de ser. A indeterminação da existência traz uma ação inconsciente daquilo que lhe cabe. Segundo Prates (2019), quando a escolha ocorre de forma reflexiva, ela se dá a partir da necessidade de Liberdade, sendo o indivíduo detentor de um lugar de privilégios na passividade de sua formação - ser do fenômeno.

Ainda assim, ele não se abstém de sua constituição e da responsabilidade de suas escolhas. Para que possa agir com autenticidade e escolher outros modos de ser não determinados pelo social, precisa nascer existencialmente em Liberdade. $\mathrm{O}$ nascimento existencial ocorre aproximadamente aos oito anos de idade, quando a criança rompe com a placenta social com a qual se relacionava até então, objetivando forjar seu projeto existencial e nascer para um mundo onde buscará suas próprias relações (SHNEIDER, 2011).

O existencialismo vê o sujeito fora das convenções, sendo sua constituição forjada em uma relação dialética entre o universal e o individual. A consciência e o mundo surgem simultaneamente e o indivíduo é produto e produtor do meio. Essa posição de Liberdade coloca o indivíduo na angústia, que é a "atmosfera ou estado que define a situação de Liberdade em que todo homem se encontra. Somente a angústia anuncia a existência em situação de precariedade, de indeterminação, de liberdade" (PROTÁSIO, 2014, p. 216). Tomar consciência dessa posição é estabelecer a relação com o mundo de forma autêntica (SARTRE, 1997).

A consciência é móbil e está fora no mundo. A partir do objeto apreendido, rompe com a ideia de uma existência pronta, essencialmente dada, que se dará na abertura para a Liberdade de ser (PRATES, 2019). Ainda no que diz respeito à constituição do sujeito, cabe destacar que a consciência transcende a si mesma pela intencionalidade, que, mais do que o objeto apreendido, é o que se faz dessa apreensão. "Consciência é liberdade, não apenas como possibilidade em relação ao mundo, mas, sobretudo, como o princípio da ação que se torna constitutiva do objeto mundo" (CORBIANO; BERGAMO, p. 271).

Tomando por base o caminho teórico discutido até aqui, a partir de agora será feita uma reflexão acerca das determinações sociais, da privação de liberdade na adolescência e da Liberdade para Sartre (1997). Para isso, a história de Saint Genet, paciente de papel de Jean Paul Sartre, será a base para a reflexão. Cabe ressaltar que Sartre foi filósofo e não psicólogo, e por isso não atendeu clinicamente. No entanto, em sua trajetória, escreveu sobre o cotidiano e sobre pessoas reais e suas experiências (SHNEIDER, 2002).

Ao "roubar" uma faca na cozinha, por volta dos sete anos de idade, Genet "vestiu-se" de uma determinação dada a ele pelo pai: a de ladrão. A partir de então, apreendeu para si o que foi dito sobre ele e passou a cometer diversos delitos (PRATES, 2019). Genet era filho de pai desconhecido e mãe prostituta e foi adotado por uma família rural, tendo uma educação baseada no preceito de moralidade. Quando percebeu que não podia ser o que objetivava, tomou para si o que a sociedade disse que era: ladrão. Sua inclinação anterior ao bem foi interrompida pela impossibilidade de ter aquilo que seria bom. Decidiu, então, roubar para sustentar uma posição de benevolência. "Tem-se o bem por que se é herdeiro legítimo e, reciprocamente, é-se modelado pelo que tem" (SARTRE, 2002, p. 23 apud PRATES, 2019, p. 204).

Genet, mesmo se "vestindo" daquilo que fizeram dele, nos mostra que, mesmo dentro das facticidades, é possível escolher. Neste caso, escolher ser honesto ou ladrão, tendo consciência da responsabilidade que cada opção traz consigo. Segundo descrito por Prates (2019), o trânsito entre o mal e o bem e entre a escolha e a não escolha pode criar um caminho de transcendência. Genet não se preocupou com o delito em si, mas com a satisfação que teria a partir dele. Compreende-se, nesse sentido, que os limites entre o ético e o estético caminham juntos à medida que, em cada escolha, o indivíduo atribui gostos, formas, imagens e símbolos (PRATES, 2019). Ademais, a convergência entre ser ontologicamente livre e experimentar-se psicologicamente "determinado" mostra-se na reflexão da história de Genet, que convida à escolha do indivíduo e à maneira que se posiciona frente às determinações (SHNEIDER, 2006).

Toda escolha é coletiva, pois afeta o mundo e é dada frente a um universo de possibilidades. A escolha de uma coisa e não de outra diz sobre sua autonomia e não sobre seu fim, onde ser livre não é fazer o que se quer, mas querer o que se faz (SARTRE, 1997). Com base em Sartre (1997), a experiência humana tem início nos entraves e nas atribulações que não são escolhidos quando lançados à existência. No entanto, a forma como acontecerá essa relação de escolhas do ser-no-mundo estabelecerá as possibilidades de ser do sujeito.

Saint Genet, constituído na infância pelo meio 
familiar enquanto determinante do projeto de ser, apropriou-se da figura do ladrão e por anos cometeu inúmeros delitos. Com isso, sua escolha reflete na busca por um projeto existencial próprio. Mais tarde, já na prisão, transcendeu a existência e adotou um novo modo ser, mostrando que a Liberdade é sua condenação enquanto possibilidade de escolha de ser (SHNEIDER, 2006).

\section{Nota}

1. Para uma diferenciação didática, neste trabalho liberdade com 1 minúsculo está sendo tomada como liberdade judicial e com L maiúsculo a Liberdade existencial

\section{Considerações finais}

A partir das enunciações teóricas aqui percorridas, reflete-se que, apesar das determinações sociais e das facticidades, é possível pensar numa adolescência que vivencia o conflito com a lei para além de entificações, ou seja, para além do que lhe foi dado. A existência se constitui na relação entre sujeito e mundo, no desenrolar das experiências através das quais o adolescente irá apropriar-se ou não da sua condição de Liberdade e da responsabilidade pelas suas escolhas (FEIJOO, 2011). A adolescência, tal como se mostra - em abertura, sem qualquer modo prévio -, permite o desvelamento de novas possibilidades de vir a ser.

No entendimento existencial, a Liberdade ocupase da indeterminação, direcionando o homem para a responsabilidade de tudo que experimenta enquanto ser-no-mundo (FEIJOO, 2011). A Liberdade tem como premissa a possibilidade de escolha por uma coisa ou outra, de "vestir" ou não o que mundo oferece. A realidade da adolescência pobre e preta influencia as escolhas, mas não determina o projeto existencial. Vale ainda dizer, com base em Sartre (apud FEIJOO, 2011), que a busca por uma identidade própria aponta para o fato de que "o inferno são os outros", pois é na relação com o mundo que nos enxergamos determinados.

O homem, desde o início da vida, é atravessado por questões históricas e determinismos sociais. E, conforme foi discutido, o contexto do adolescente em conflito com a lei está inserido numa conjuntura de expressão reducionista. $\mathrm{O}$ que os outros fazem de mim pode ser compreendido como uma manifestação do fenômeno de ser - que, de acordo com Sartre (1997, p.18), é "uma aparição do ser descritível como tal", que pode implicar numa consciência espontânea, ou seja, não refletida, tornando o ser cristalizado nos fenômenos. Já o que faço com o que os outros fizeram de mim aponta para o ser do fenômeno, que não se limita a um único processo ou descrição objetiva, visto que, ainda na ausência, a existência se faz presente.
Sartre (1997) nos traz ainda que, mesmo que o ser do fenômeno exista correlacionando-se com os inúmeros fenômenos de ser, é de suma importância que se rompa com a condição de aparição, transcendendo a existência livremente nas possibilidades e colocando-se frente às consciências, relacionando-se com o mundo da maneira possível

\section{Referências}

AGUIAR, E. N. Crianças de ninguém: roubo, abandono e exclusão no desenho infantil sob a ótica sartreana. In: FEIJOO, Ana Maria Lopez Calvo de. (Org.). Interpretações Fenomenológicas Existenciais para o Sofrimento Psíquico na Atualidade. Rio de Janeiro: GdN, 2008. v. 01, p. 202-231.

AZEVEDO, C. R. S.; AMORIM, T. R. S.;ALBERTO, M. F. P. Adolescência e Ato Infracional: violência Institucional e Subjetividade em Foco. Psicologia: ciência e profissão, v. 37, n. 3, p. 579-594, jul/set., 2017.

BARBOSA, M. R. Violência de Estado: dos discursos sociais às leituras individuais. 2013. 274 f. Tese (Doutorado em Psicologia) - Escola de Psicologia, Universidade do Minho, Braga, 2013.

BRASIL. Código de Menores. Lei n. 6.697. Brasília: 10 de outubro de 1979.

BRASIL. Conselho Nacional dos Direitos da Criança e do Adolescente. Sistema Nacional de Atendimento Socioeducativo. Resolução n. ${ }^{\mathbf{1}}$ 119, de 11 de dezembro de 2006. Brasília: 2006.

Estatuto da Criança e do Adolescente. Lei Federal no 8.069 , de 13

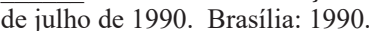

Levantamento anual Sinase 2017. Ministério da Mulher, da Família e dos Direitos Humanos (MMFDH). Brasília: Ministério da Mulher, da Família e dos Direitos Humanos. Brasília: 2019

CÉSAR, M. R. A. Da adolescência em perigo à adolescência perigosa. Educar em revista, n. 15, dez-jan, 1999.

COIMBRA, C. M. B.; NASCIMENTO, M. L. Ser jovem, ser pobre é ser perigoso? Jovenes, Revista de Estudios sobre Juventud, p. 338-355, 2005.

CFP. Conselho Federal de Psicologia. V Seminário Nacional. Psicologia e Políticas Públicas: Subjetividade, Cidadania e Políticas Públicas. Brasília CFP, 2011.

CORBIANO, S. A. M.; BERGAMO, T. M. M. Consciência, Intencionalidade e Liberdade: Contribuições de Sartre na formação do sujeito. Educar em Revista, Curitiba, Brasil, n. 59, p. 263-275, jan./mar, 2016.

COUTINHO, L. G. Adolescência e Errância. Rio de Janeiro: Nau/FAPERJ, 2009 .

CUSTODIO, A. Teoria da proteção integral: pressuposto para compreensão do direito da criança e do adolescente. Revista do Direito, Santa Cruz do Sul, p. 22-43, jan. 2008.

IBGE. PNAD Contínua 2018: $10 \%$ da população concentram $43,1 \%$ da massa de rendimentos do país. Disponível em: https://agenciadenoticias. ibge.gov.br/agencia-sala-de-imprensa/2013-agencia-de-noticias/ releases/25700-pnad-continua-2018-10-da-populacao-concentram-43-1-damassa-de-rendimentos-do-pais. Acesso em: 11 set. 2020.

FEIJOO, A. M. L. C. A Clínica Psicológica em uma Perspectiva Existencial. Revista da Abordagem Gestáltica, p.185-192, jul-dez, 2011.

MINAYO, M. C. S. Violência contra crianças e adolescentes: questão social, questão de saúde. Revista Brasileira Materno Infantil, Recife, v. 1, n. 2, mai./ago. 2001

MOREIRA, C. A. B. D. As medidas socioeducativas e as violações de direitos de adolescentes. In: V Jornada Internacional de Políticas Públicas, 2011, São Luiz, Maranhão. Anais [...]. São Luiz: UFMA, 2011.

PRATES, M. Genet e o Mal: Sartre Entre a Ética e a Estética. Trans/Form/ 
Ação, v. 42, n. 3, p. 191-218, jul./set. 2019.

PROTASIO, M. Mo. A psicologia indicada por kierkegaard em algumas de suas obras. Revista da abordagem Gestáltica - Phenomenological Studies, p. 213-220, jul-dez, 2014

SARTRE, J. P. O ser e o nada: ensaio de ontologia fenomenológica. 9. ed. Petrópolis: Vozes, 1997.

SHNEIDER, D. R. Liberdade e dinâmica psicológica em Sartre. Natureza Humana, v. 8, n. 2 p. 283-314, jul-dez, 2006.

Novas Perspectivas para a Psicologia Clínica: um estudo a partir da obra "Saint Genet: comédien et martyr" de Jean-Paul. Tese. PUC-SP, São Paulo, 2002. Disponível em http://www.psiclin.ufsc.br/files/2010/05/Tese. pdf. Acesso em: 01 fev. 2020.

Sartre e a psicologia clínica. Florianópolis: UFSC, 2011.

SPOSATO, K. B. (Org.). Guia teórico e prático de medidas socioeducativas. 2004. Disponível em: http://www.crianca.mppr.mp.br/arquivos/File/ politica socioeducativa/doutrina/Guia teorico e pratico de medidas socioeducativas_SPOSATO.pdf. Acesso em: 10 fev. 2020

VIEIRA, I. IBGE: negros são $17 \%$ dos mais ricos e três quartos da população mais pobre. Disponível em: https://agenciabrasil.ebc.com.br/ geral/noticia/2016-12/ibge-negros-sao-17-dos-mais-ricos-e-tres-quartos-dapopulacao-mais-pobre. Acesso em: 09 set. 2020.

VITELLI, C. Adolescência e identidades estéticas do cotidiano. Educação em Revista, v. 25, n. 03, p. 43-74, dez. 2009. 